\title{
XXVIII. ADDITIONAL OBSERVATIONS ON THE SEPTIC- AEMIA IN HUMAN PLAGUE WITH AN ACCOUNT OF EXPERIMENTS ON THE INFECTIVITY OF THE EXCRETA.
}

IN a previous paper (This Journal, vol. vI. p. 524) we have given an account of the quantitative estimation of plague bacilli in the blood of 16 septicaemic cases. It remains now to supplement this number with a further series and to add some observations on the infectivity of the urine and faeces.

\section{Part I. Further observations on the septicaemia in HUMAN PLAGUE.}

On account of the additional work involved in examining the excreta, the technique of the blood examinations previously described was discontinued and the following simpler method was used. By means of a sterilised syringe 2 c.c. of blood was removed from a suitable vein at the bend of the elbow, and $0 \cdot 1$ c.c. of blood, carefully measured by the graduation on the stem of the syringe, was transferred to each of two sloped dry agar tubes, the blood being spread as uniformly as possible over the surface of the tubes by shaking them. A specimen was then prepared for microscopical examination. The agar tubes after incubation were examined and subcultures of any colonies that had appeared were sown into flasks for the stalactite test. Animal tests (cutaneous or subcutaneous inoculation of guinea-pigs) were resorted to if considered necessary.

The details of the present series have been arranged in Tables I and II.

The data relating to the fatal cases, whose blood was examined on at least two occasions, are collected in Table I in such a form that the course of the septicaemia is easily seen. 
Usually, as is to be expected, the septicaemia goes on increasing till death. Case 9, however, affords an illustration of a type to which we referred in our former paper, namely, a septicaemia that diminishes as the disease progresses. Case 10 is a remarkable one. Bacilli were

TABLE I. Fatal cases in which B. pestis was recovered from the blood.

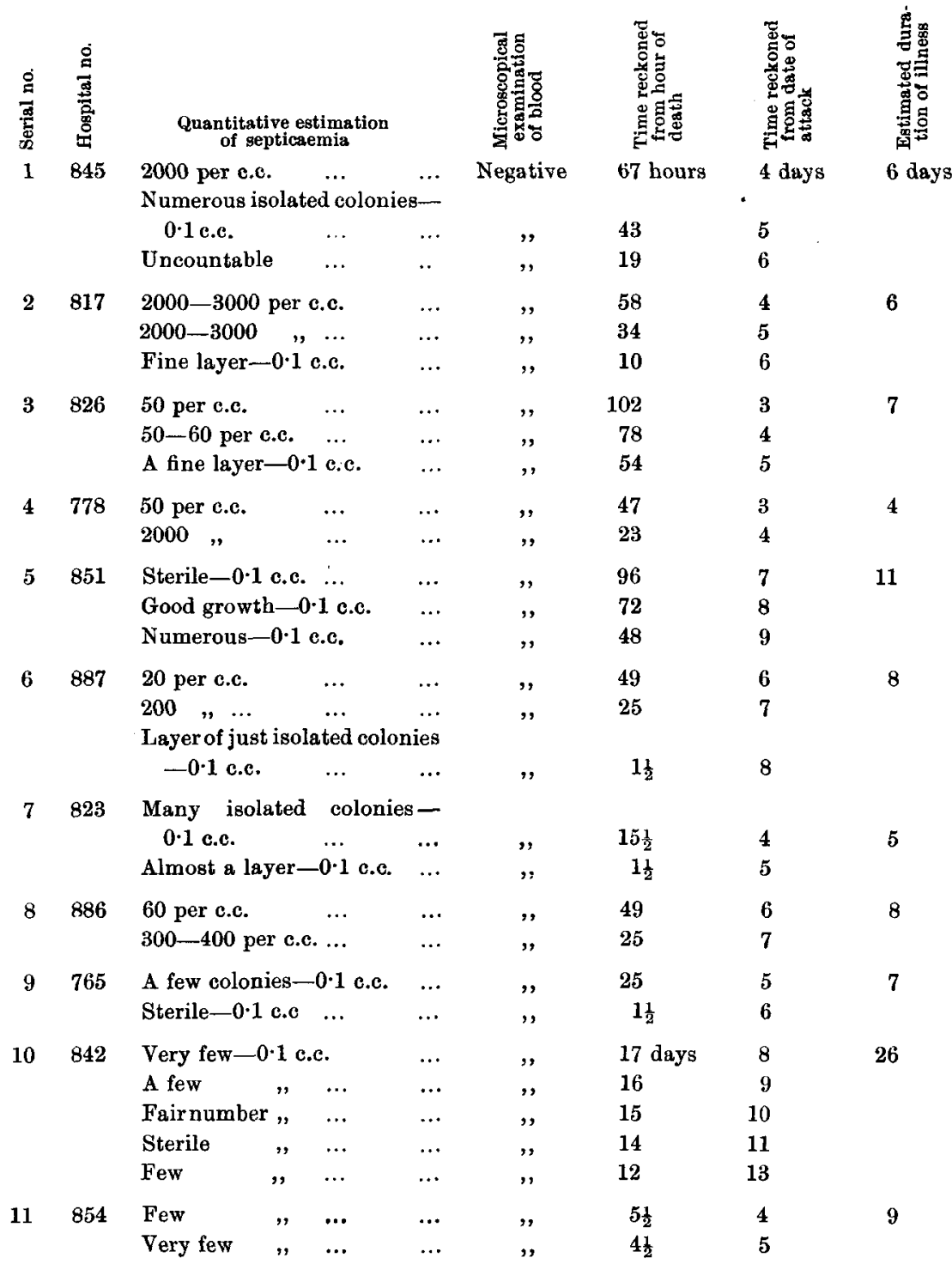


TABLE II. Giving results of examination of samples of blood (urine and faeces not examined). Quantitative estimation
of septicaemia
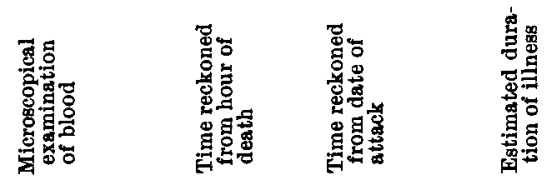

Group I. Very numerous colonies.

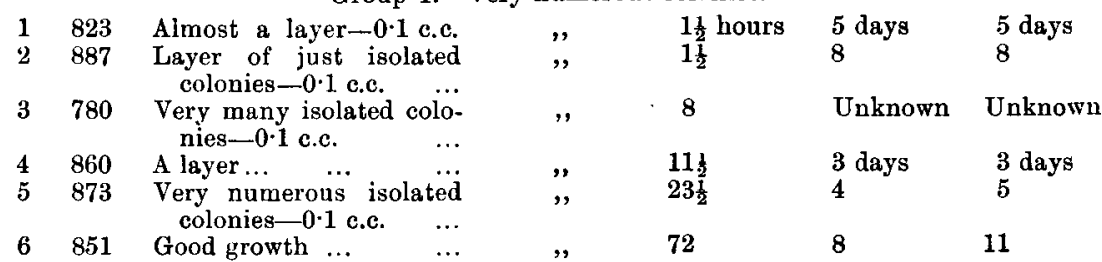

Group II. Numerous colonies.

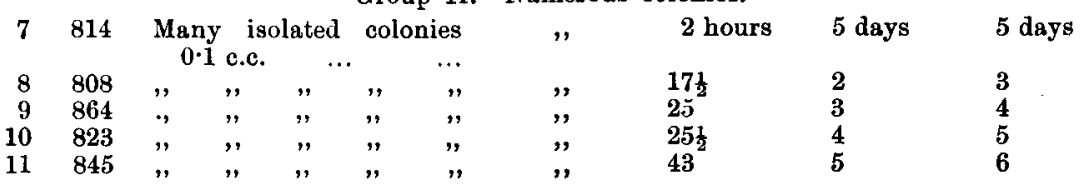

Group III. Fairly numerous colonies.

\begin{tabular}{|c|c|c|c|c|c|c|}
\hline 862 & 1000-2000 per c.c. & $\cdots$ & , & $\begin{array}{l}\text { Just before } \\
\text { death }\end{array}$ & Unknown & Unknown \\
\hline 818 & $400-500$ & & ," & 27 hours & 4 days & 5 days \\
\hline 856 & $500-600$ & $\ldots$ &, & 29 & Unknown & Unknown \\
\hline 868 & $1000-2000$ & $\ldots$ & 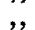 & 30 & 5 days & 6 days \\
\hline 817 & $2000-3000$ & $\ldots$ &, & 34 & $\mathbf{5}$ & 6 \\
\hline 817 & $2000-3000$ & $\ldots$ & ," & 58 & 4 & 6 \\
\hline 845 & About 2000 & .. &, & 67 & 4 & 6 \\
\hline 826 & $500-600$ & .. & 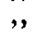 & 78 & 4 & 7 \\
\hline 842 & Fair number- 0.1 c.c. & .. & ," & 15 days & 11 & 26 \\
\hline 866 & $500-600$ per c.c. & & ,, & Recovery & 2 & Recovery \\
\hline
\end{tabular}

Group IV. A few colonies.

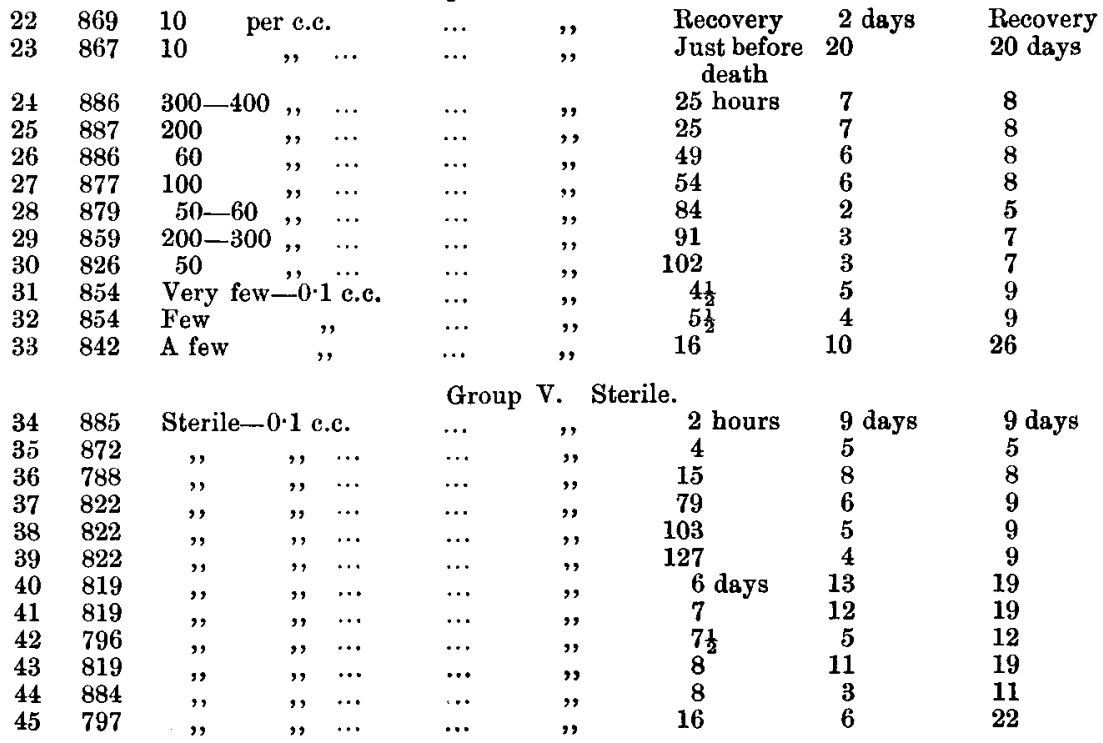


present in the blood 17 days before death and they continued to be present till at least 12 days before death occurred. This case also exemplifies the type of septicaemia referred to in the account of the preliminary series as "irregular" or "fluctuating" (compare case 18, Table II, vol. vi. p. 527 of previous paper).

Table II gives in a convenient form the results of a considerable number of examinations of blood arranged with reference to individual samples. The samples have been distributed into 5 groups, according to whether the colonies which developed from $0 \cdot 1$ c.c. of blood were "very numerous," "numerous," "fairly numerous," "few" or none. Further, the samples in each group are set forth in a sequence which has reference to the time, reckoned from the hour of death, when the specimen was taken.

No. 6 is noteworthy as illustrating the fact that a marked septicaemia may be present a considerable period before death,- -in this case 72 hours. Nos. 21 and 22 deserve special notice since they are examples of septicaemic cases which ended in recovery. Bacilli were present in the blood of both ( 10 colonies per c.c. and 500-600 colonies per c.c.) 2 days after the reputed date of attack.

TABLE III. Showing averages of "number of hours before death" and of "days of illness" for each Group in Table II.

Group
I
II
III
IV

$\quad \begin{gathered}\text { Colonies of } \\ \text { B. pestis }\end{gathered}$
Very numerous
Numerous
Fairly numerous
Few
None

$\begin{array}{cc}\begin{array}{c}\text { Hours } \\ \text { before death }\end{array} & \begin{array}{c}\text { Days of } \\ \text { illness }\end{array} \\ 19 \cdot 7 \text { hours } & 6 \cdot 4 \text { days } \\ 22 \cdot 6 & 4 \cdot 6 \\ 85 \cdot 4 & 10 \cdot 3 \\ 105 \cdot 4 & 11 \cdot 0 \\ 132 \cdot 5 & 12 \cdot 6\end{array}$

An average has been struck for each group of the number of hours before death when the specimens were taken, and similarly of the estimated number of days the illness lasted. The results are shown in Table III. From the figures presented therein two conclusions seem warranted, namely (1) that the degree of septicaemia bears a definite relation to the period before death at which it is determined, and (2) that the degree of septicaemia bears a definite relation to the acuteness of the illness.

Lastly, the tables clearly confirm the judgment we passed in the account of the earlier series on the value of the microscopical examination of the blood, to the effect that this method of examination is quite untrustworthy as an index of the severity of septicaemia which may be present. 


\section{Part II. ON THE INFECTIVIty OF THE URINE AND FAECES IN HUMAN PLAGUE.}

The following account summarises the work of previous observers on this subject.

Wilm (1897) stated that he found $B$. pestis in the urine 4 to 6 weeks after the cessation of febrile symptoms. The Austrian Plague Commission (1900) attempted the cultivation of $B$. pestis from the urine of 17 cases post mortem; they succeeded in 5 cases. They made fairly numerous attempts to cultivate the bacillus from the urine of patients before death but never succeeded. The German Plague Commission (1899) obtained a pure culture of $B$. pestis from the urine of only 2 patients. Most of their attempts at cultivation either from patients or at the post mortem yielded no results, the cultures remaining sterile or containing adventitious bacteria. The Indian Plague Commission (1901) examined 60 specimens of urine by cultivation methods, but were able to isolate $B$. pestis in only 3 cases. Tidswell (1900) examined the urine of 29 cases by cultural and inoculation tests but in every instance failed to prove that plague bacilli were present.

With regard to the examination of faeces, the Austrian Plague Commission investigated 8 cases in the post-mortem room in addition to fairly numerous cases before death. They never succeeded in demonstrating the presence of the plague bacillus by cultural methods. The plan of inoculating guinea-pigs cutaneously, which they brought into prominence after their return to Vienna, was not employed by them in Bombay. The German Plague Commission using cultural and animal tests were also unsuccessful. The faeces were examined by the Indian Plague Commission in 4 cases but without success. Tidswell (1900) by means of plates and by microscopical examination investigated the faeces of 20 cases with uniformly negative results.

This brief review of the literature of the subject makes it plain that unusual difficulties surround the examination for plague bacilli of the urine and faeces.

We decided to attack the problem on somewhat different lines from those pursued by our predecessors. Cultivation methods were entirely dispensed with, and animal tests were substituted for them. The guinea-pig, on account of its extreme susceptibility, was used as the experimental animal throughout.

Four series of experiments were carried out, namely :-

I. The cutaneous inoculation of graduated quantities of urine.

Journ. of Hyg. viII 
II. The cutaneous inoculation of faeces.

III. The subcutaneous inoculation of 1 c.c. of urine with, at the same time, the cutaneous inoculation of a control guinea-pig with $0 \cdot 1$ c.c. of the same sample of urine.

IV. Contact experiments in a flea-free godown with the soiled linen of fatal cases.

Our methods were as follows:-

Series $I$. After blood had been withdrawn from the patient in the manner already described, a Jacques' catheter, previously sterilised by boiling, was passed into the bladder and the urine allowed to flow directly into a sterile test-tube. The subsequent examination was carried out in a room adjoining the ward within a few minutes after the withdrawal of the urine. 1 c.c., 0.1 c.c. and 0.01 c.c. of each specimen of urine were measured off into three sterile watch-glasses by means of a graduated diluting pipette. After being made up to a convenient bulk with sterile broth each quantity was injected into the subcutaneous tissues of the thigh of each of three guinea-pigs. If microscopical examination showed that numerous bacilli were present in the blood higher dilutions were made, but this was rarely found necessary. The guinea-pigs after inoculation were returned to the laboratory, where they were kept under observation. In a few cases only the animals died as the result of the entrance into the tissues of organisms other than plague; on the whole the method proved quite satisfactory.

Series II. After the urine had been withdrawn from the patient, a sterilised glass tube (of about $6 \mathrm{~mm}$. diam., except at one end where it narrowed in a slightly cone-shaped manner) was passed into the rectum as gently as possible so as to avoid accidental abrasions. As a matter of fact, probably from abrasions of the congested mucous membrane of the rectum caused by the insertion of the tube, the faeces were sometimes found to be blood-stained. We were generally able by this method to obtain a quantity of faeces sufficient for a test. Two guinea-pigs were used for every specimen of faeces examined, the faeces being well rubbed into a slightly scarified area of skin on the animal's abdomen.

Series III. 1 c.c. of the freshly drawn urine was injected subcutaneously into the thigh of a guinea-pig. At the same time $0 \cdot 1$ c.c. of the same sample was well rubbed into a shaved and scarified area about $\frac{1}{3}$ inch in diameter on the control guinea-pig's abdomen.

Series $I V$. Fifteen guinea-pigs were confined in a flea-proof godown in the laboratory compound. The bedding, recently soiled by the excreta of acute cases just before death, was added daily, each lot of bedding being kept in the godown for 48 hours. 
Our observations and the results of the experiments in Series I and II have been tabulated in Table IV, in groups which make it easy to compare the four essential points: $(a)$ infectivity ${ }^{1}$ of urine, $(b)$ infectivity of faeces, (c) quantitative estimation of the septicaemia and (d) microscopical examination of the blood.

It will be seen that the blood and urine of 27 patients were examined and that the urine of 8 was infective, i.e. $29 \cdot 6 \%$. On 7 occasions out of 22 on which a growth of B. pestis was obtained from the blood, the urine proved at the same time to be infective, i.e. the urine was infective in $31.8 \%$ of the septicaemic cases. In No. 8 no culture was obtained from the blood and yet 0.01 c.c. of the urine killed a guinea-pig. The explanation suggests itself that this was an instance of a diminishing septicaemia. In 15 instances in which a culture was obtained from the blood, the urine proved to be non-infective. The urine of No. 3 was highly infective,--0.0001 c.c. killing a guinea-pig of plague. This was associated with a marked septicaemia and the case is notable also as providing an example of a rare event in our experiencethe presence of very numerous $B$. pestis on microscopical examination. The samples were taken 2 hours before death. It is evident from a study of the table that most of the cases whose urine proved to be infective had a severe septicaemia at the time of examination. This conclusion is warranted not only from the result of the cultural tests, but from the result of the microscopical examination, as may be seen from a comparison of Groups II and III in the Table. We may state, therefore, that when the urine is infective, the degree of infectivity stands in a direct relation to the degree of septicaemia. On the other hand, it would appear that at the moment of examination the blood may contain many bacilli and yet the urine may be non-infective. This receives illustration in Nos. 9, 10, 17, 18, 19, 22 and 23.

A comparison of Groups II and III from the point of view of the number of hours before death the samples were examined reveals a striking difference. This comparison shows that the most highly infective samples of urine were examined within 5 hours of death,--the interval before death being much longer in the case of the samples of Group III. The numbers in each group are admittedly small, but the

\footnotetext{
I For the sake of convenience we will employ the term "infective" as indicating that 1 c.c. or less of the urine killed a guinea-pig with plague, and the term "non-infective" to indicate that the guinea-pig was not affected by the inoculation of this amount. A similar meaning is attached to the terms in the case of the faeces. Again for the purpose of the present paper the term "septicaemia" may be allowed to mean that a growth occurred in $0 \cdot 1$ c.c. of blood.
} 


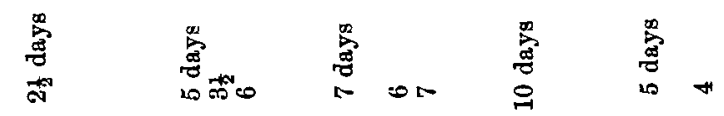

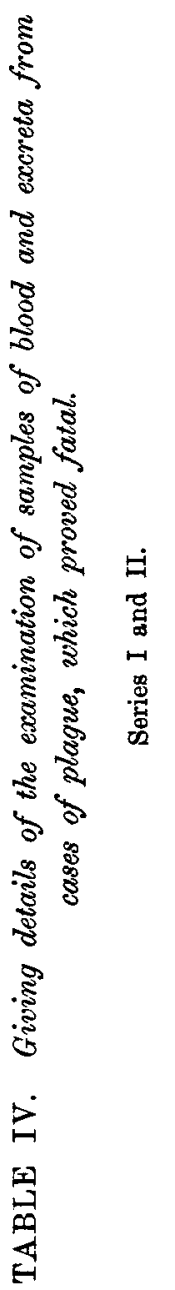

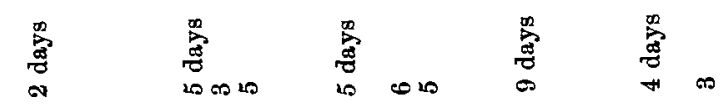

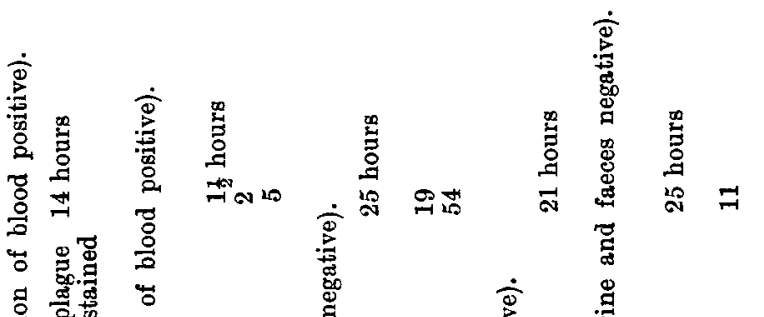

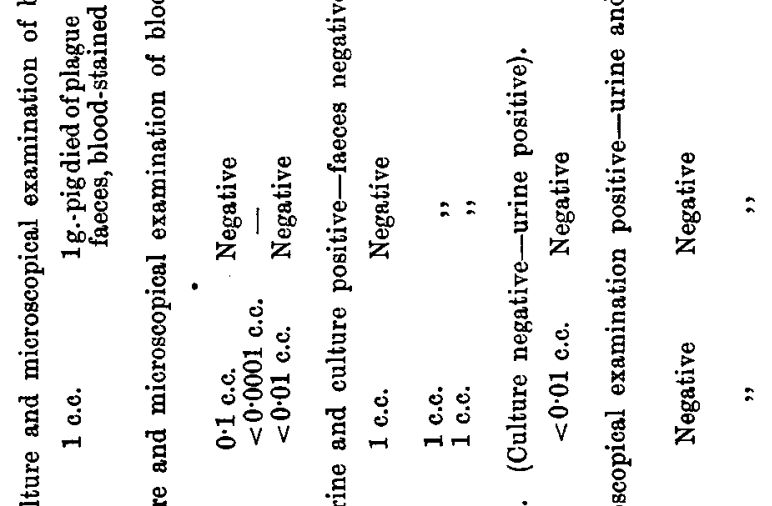

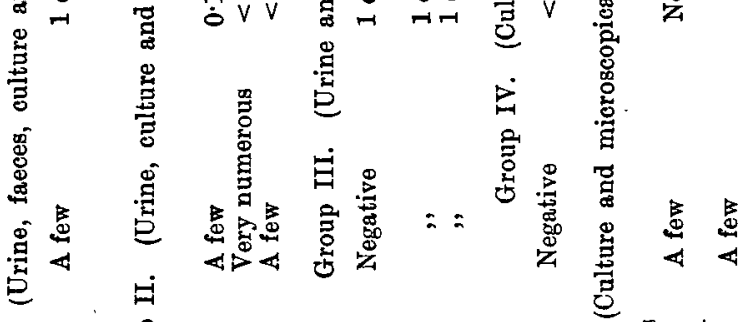

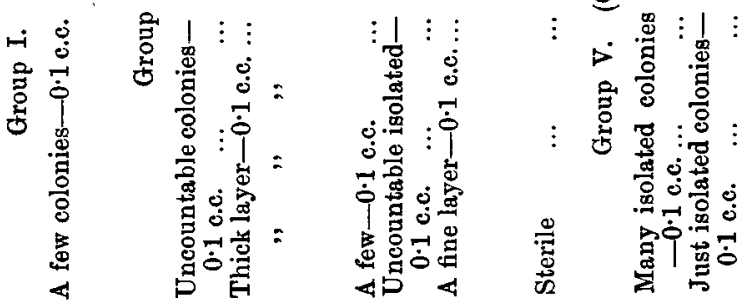

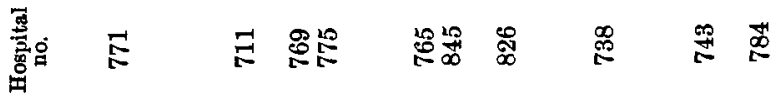

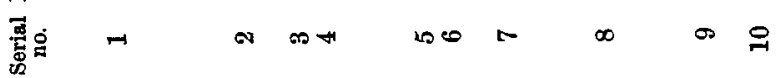


Reports on Plague Investigations in India

恕

$\sin \infty \pi+\sin ^{\circ}$

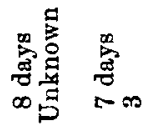

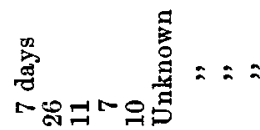

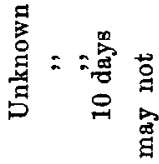

总

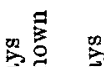

点

告

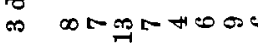

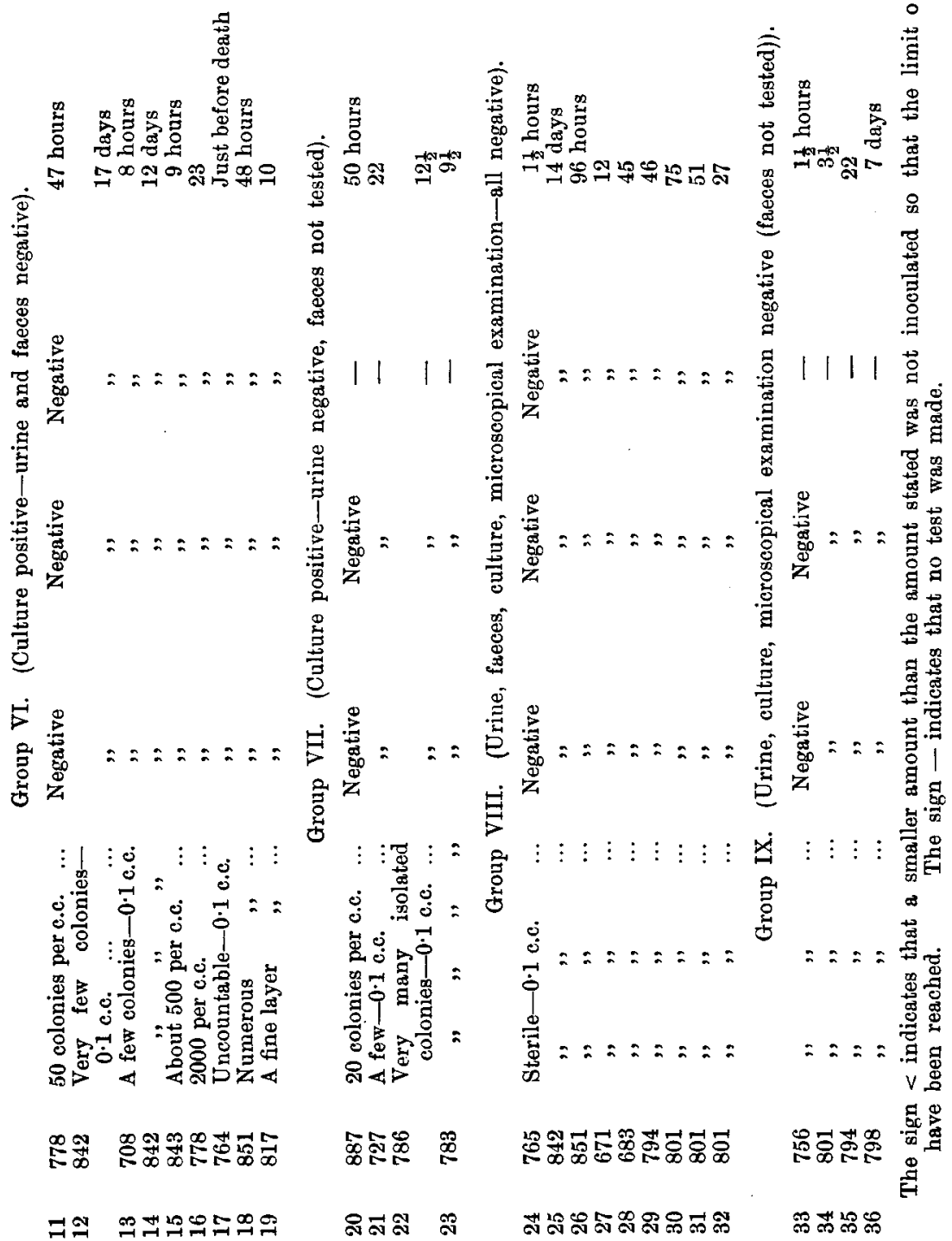


deduction, that the maximum infectivity of the urine occurs within a few hours of death, is probably not far wide of the mark, since this result doubtless depends on the fact that the septicaemia tends to be greatest at this time, and also on the fact that the tissue changes in the kidneys, as in other organs, progressively increase till death.

Proceeding now to the consideration of the infectivity of the faeces, it may be remarked that on one occasion only did a guinea-pig die as the result of inoculation. Even in this case we are not satisfied that the faeces were truly infective; because they had the appearance of being stained with blood from an accidental abrasion of the rectum. It may be added that the urine of this patient was not highly infective and that the septicaemia was not very severe. The blood and faeces of 20 patients were examined. We may say then that the faeces were not infective in at least $95 \%$ of the patients examined. In 16 instances, in which the faeces were examined, the corresponding specimens of blood yielded a culture,-in other words, assuming that the faeces of No. 1 were really infective, the samples of faeces were infective in only $6 \%$ of the septicaemic cases. We are justified then in concluding that the urine possesses greater infective properties than the faeces judging from the results obtained by the methods used in these experiments.

The urine of No. 3, Table IV, contained numerous plague bacilli and it is possible that in such a case the attendants might be in danger of contracting plague pneumonia from the spraying of plague bacilli in the air during the act of micturition.

It is necessary now to consider the bearing of these results related above on the question of the danger of infection from contact with excreta of plague cases under natural conditions. We do not think that any conclusions can be drawn from the experiments with urine in Series I as to the infectivity of the urine in relation to the spread of the epidemic, because the method of subcutaneous inoculation is a method which cannot occur in nature except from some untoward accident. The experiments are of interest, however, since they throw light upon the relation of the septicaemia to the bacilluria and since they show that in nearly $30 \%$ of the cases examined the urine contained virulent $B$. pestis. It would appear from the experiments with faeces that the infectivity of the faeces is very slight and that, therefore, they cannot be regarded as a source of danger in the spread of plague. In order to imitate more closely a conceivable mode of infection by urine in nature, the experiments in Series III and in Series IV were carried out. In the former 
Reports on Plague Investigations in India 231
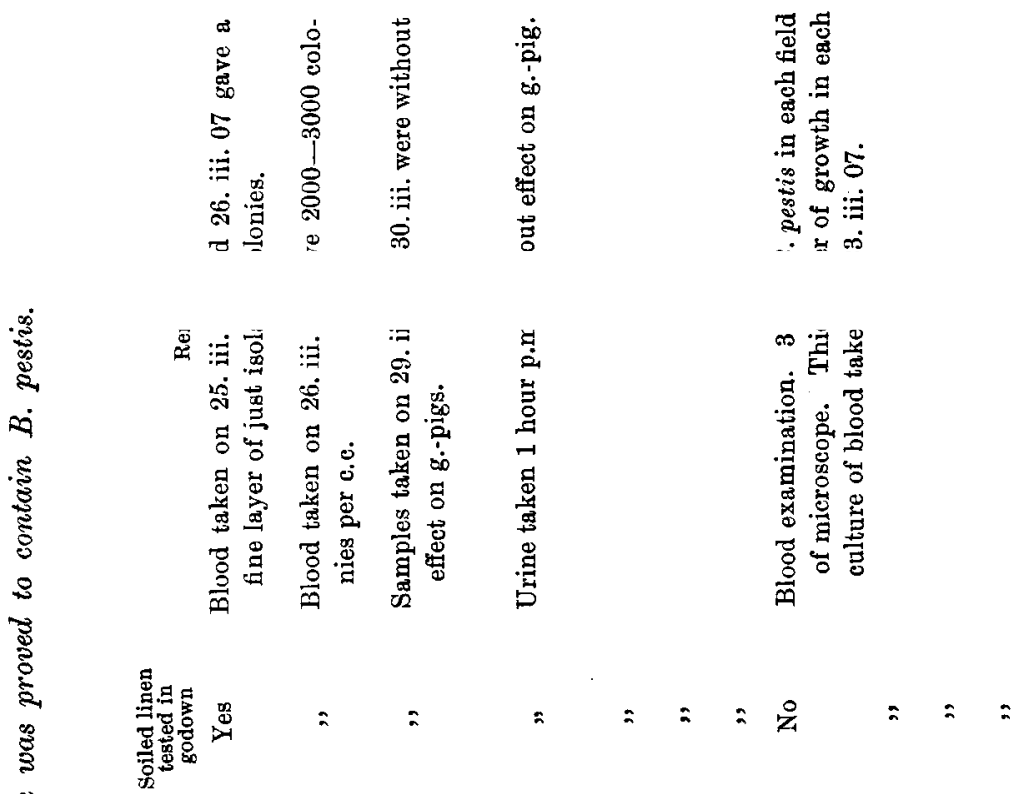

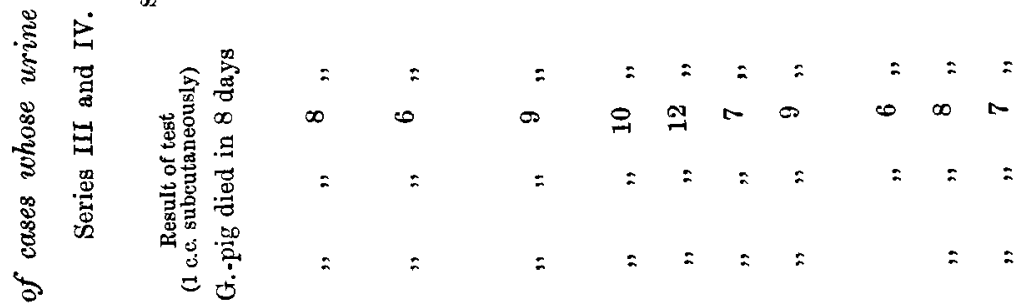

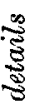
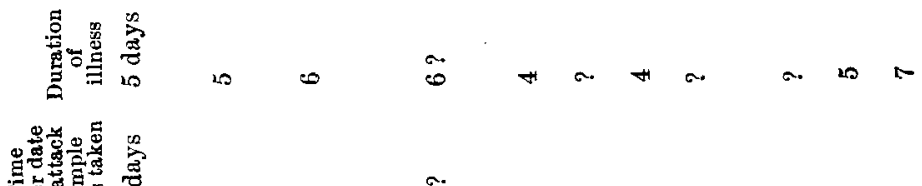

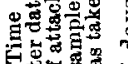

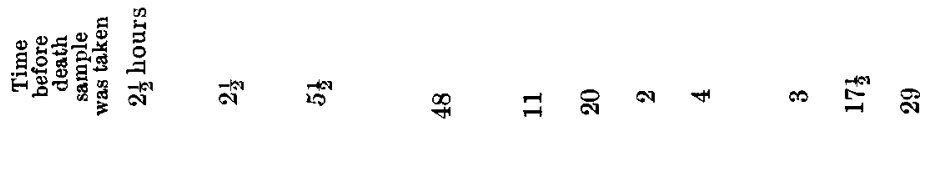

츙ㅎㅇ 555 555555555

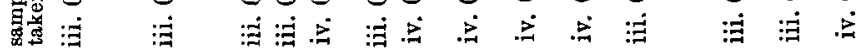

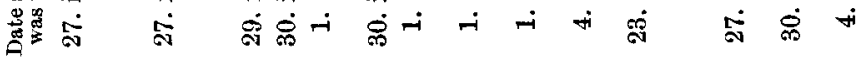

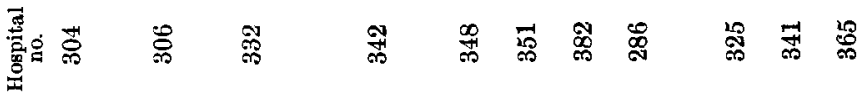


TABLE VI. Giving details of cases whose urine on testing was not proved to contain $B$. pestis.

Series III and IV.

\begin{tabular}{|c|c|c|c|}
\hline 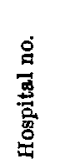 & 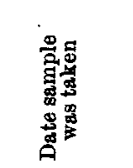 & 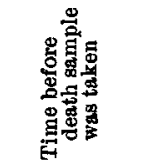 & 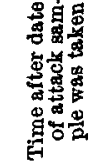 \\
\hline 284 & 28. iii. 07 & 21 hours & 7 days \\
\hline 289 & $\begin{array}{l}27 . \text { iii. } 07 \\
29 . \text { iii. } 07 \\
30 \text {. iii. } 07\end{array}$ & $\begin{array}{l}9 \\
7 \\
6\end{array}$ & $\begin{array}{r}8 \\
10 \\
11\end{array}$ \\
\hline 250 & 28. iii. 07 & 2 days & 12 \\
\hline 301 & $\begin{array}{l}\text { 27. iii. } 07 \\
\text { 28. iii. } 07 \\
\text { 29. iii. } 07 \\
\text { 30. iii. } 07\end{array}$ & $\begin{array}{l}5 \\
4 \\
3 \\
2\end{array}$ & $\begin{array}{l}5 \\
6 \\
7 \\
8\end{array}$ \\
\hline 357 & 1. iv. 07 & $\begin{array}{l}\text { Just before } \\
\text { death }\end{array}$ & 2 \\
\hline 358 & $\begin{array}{l}\text { 1. iv. } 07 \\
\text { 2. iv. } 07 \\
\text { 3. iv. } 07 \\
\text { 4. iv. } 07\end{array}$ & $\begin{array}{l}4 \text { days } \\
3 \\
2 \\
19 \text { hours }\end{array}$ & $\begin{array}{l}2 \\
3 \\
4 \\
5\end{array}$ \\
\hline 74 & 23. iii. 07 & $?$ & ? \\
\hline
\end{tabular}

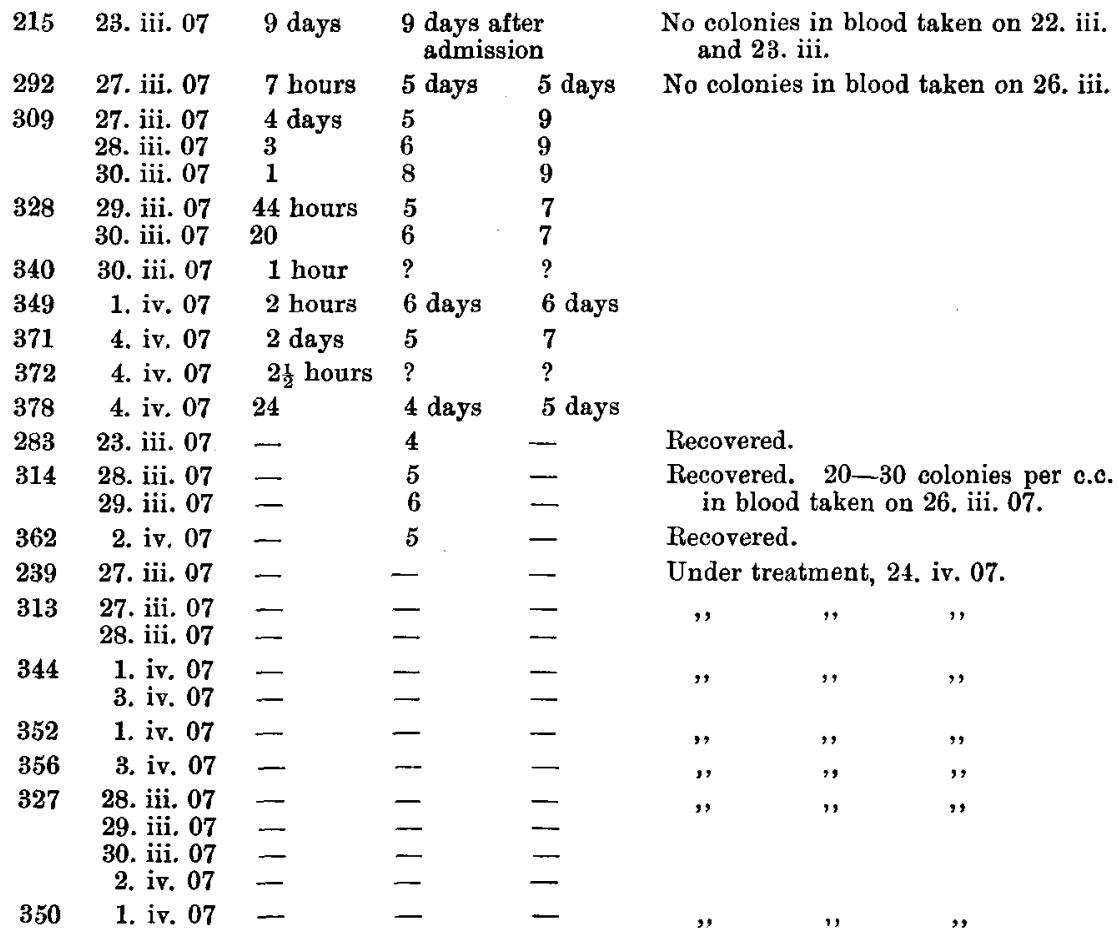


series, with a few exceptions, the examination of the blood was omitted; the samples were, however, invariably taken from patients who were acutely ill of the disease. The results are tabulated in Tables V, VI and VII. The experiments in these series were purposely carried out in order to compare the infectivity of the urine by cutaneous inoculation - a method comparable to a conceivable mode of infection in naturewith the results obtained by subcutaneous inoculation,-a method which, as we have said, can hardly occur in nature.

We may note that 57 samples of urine, derived from 37 cases, were examined. Eleven samples $(19.3 \%)$ killed the guinea-pig when inoculated subcutaneously, but in no single instance did a control animal inoculated cutaneously contract the disease. This result is very important, because it shows that a sample of urine, although it contains virulent B. pestis, may fail to give plague to a susceptible animal when rubbed into an abraded area of skin. It is interesting to note also that the guineapigs inoculated subcutaneously took an unusually long time to die, the average duration of life of the test animals working out at 8.2 days. Whether the result was due to a diminished virulence of the bacilli or to small numbers of bacilli being present in the urine, we are unable to say.

TABLE VII. Additional cases in which the soiled linen was tested in the godown; urine not tested separately.

$\begin{array}{ccc}\begin{array}{c}\text { Hospital } \\ \text { no. }\end{array} & \begin{array}{c}\text { Duration } \\ \text { of illness }\end{array} & \text { Series IV. } \\ 260 & 6 \text { days } & \begin{array}{c}\text { Thick layer of growth in blood taken; just before death B. pestis } \\ \text { fairly numerous microscopically. }\end{array} \\ 285 & 7 & \begin{array}{c}\text { A few colonies in blood taken 4 days and } 2 \text { days before death and } \\ \text { about } 500 \text { colonies per c.c. of blood taken } 24 \text { hours before death. }\end{array} \\ 369 & 4 & \\ 392 & 3 & \\ 409 & 5 & \end{array}$

The details of the cases which furnished soiled linen for the experiments in Series IV will be found in Tables V, VI and VII. As already stated, each lot of linen was kept in the godown for 48 hours. The first lot of bedding was put in on 23rd March 1907 and the last on 9th April 1907, so that the 15 animals were exposed continuously to contact with the excreta for a period of 18 days. In all 18 lots of bedding were put into the godown. In 7 cases the bedding was from patients whose urine contained virulent $B$. pestis, as proved by the death of 'a guinea-pig after subcutaneous inoculation of the urine. 
In 4 instances in addition to these, the bedding was taken from septicaemic cases. Nearly all the cases were acute and all were fatal; the bedding soiled by the patient just before death was in every instance selected for the experiment. In spite of the intimate contact with this material in a confined space none of the guinea-pigs contracted the disease.

Reference may be made here to certain experiments already described (vol. vII. p. 380), in which many of the samples of urine examined during the course of the present experiments were used to contaminate the food of Bombay rats. Even when the urine proved infective, in not a single instance did the rat suffer any harm. We may therefore conclude that little danger exists to rats of a nasal or mouth infection from contact with excreta of plague patients.

We have finally to record our thanks to Dr Khan Bahadur N. H. Choksy, M.D., Medical Officer of the Maratha Hospital, for his courtesy and kindness in placing the clinical material at our disposal and for giving us accommodation and facilities for carrying out the work at this hospital.

\section{Conclusions.}

1. A severe septicaemia may be present at a comparatively early stage of the disease and for a considerable number of hours before death.

2. The degree of septicaemia as a rule stands in an inverse relation to the interval before death the observation is made, i.e. the shorter the interval before death, the greater is the septicaemia.

3. The degree of the septicaemia stands in a direct relation to the acuteness of the illness.

4. The septicaemia is usually of a progressive type, but is occasionally of a "diminishing," "irregular" or "fluctuating" type.

5. A patient with a septicaemia may recover.

6. Microscopical examination of the blood cannot be regarded as a trustworthy index of the degree of septicaemia.

7. The urine of nearly $30 \%$ of the cases in Series I and in $19.3 \%$ of Series III contained virulent $B$. pestis, which killed test animals when inoculated subcutaneously.

8. When the urine proves to be infective by the subcutaneous method of inoculation, its degree of infectivity is directly related to the degree of septicaemia. 
9. The maximum infectivity of the urine, as tested by the subcutaneous inoculation with guinea-pigs, appears to occur within a few hours of death.

10. At a particular stage of the disease an absence of infectivity of the urine may coexist with a severe septicaemia.

11. The urine may be infective although at the time of testing a septicaemia is not present.

12. Experiments devised with the object of testing the infectivity of the excreta from the point of view of the spread of the human epidemic support the conclusion that the excreta of plague patients are ineffective in this regard. These experiments show

(a) that the faeces are rarely infective even when a septicaemia is present:

(b) that the urine-in some cases containing virulent plague bacilli-from patients acutely ill of the disease failed to infect guineapigs when rubbed into a scarified area of skin:

(c) that guinea-pigs exposed to intimate and prolonged contact with linen soiled with the excreta of moribund patients remained free from infection.

\section{REFERENCES.}

Austrian Plague Commission (1900), Examination of urine, Pt. II. B, p. 547. - Examination of faeces, Ibid.

German Plague Commission (1899), Examination of urine and faeces, p. 273.

Indian Plagde Commission (1901), Examination of urine and faeces, Vol. v. p. 95. TIDsweLL, Report of Outbreak in Sydney (1901), p. 53.

WILM (1897), Hygienisch. Rundschau, p. 217. 